\title{
Reoperation for angina after previous aortocoronary bypass surgery
}

Sir,

The review paper by Pidgeon et al (1985; 53: 269-75) raises several points. Firstly, single vein grafts represented a high number of the patients undergoing both first and second operations, and recent reports have shown a pronounced increased frequency of perioperative spasm in just this group of patients 1 - even to the extent of producing perioperative infarction-particularly in the nongrafted, often normal vessel. Was the occurrence of the 20 perioperative infarctions in this study higher in patients undergoing one or two vein grafts?

Secondly, the reasons for reoperation in this group were determined at angiography, although the relation between symptoms and the number and degree of coronary stenosis is clearly not linear. ${ }^{2}$ Have the authors considered whether dynamic causes such as coronary vasospasm might play a more dominant role in the production of symptoms severe enough to require reoperation? Vasospasm may continue to affect host and graft vessels ${ }^{3}$ and is strongly implicated in the day to day variability experienced by nearly all patients with angina. ${ }^{4}$

Thirdly, many careful studies have already confirmed the lack of relation between traditional risk factors and progression of disease after coronary artery bypass graft. ${ }^{5}$ The persistence of type A behaviour (especially hostility, cynicism, and vocal stylistics) has been found to be significantly correlated with the development of postoperative angina, ${ }^{6}$ probably due to repeated and excessive sympathoadrenal medullary response to environmental stressors. ${ }^{7}$ Certainly, behavioural factors have been found to correlate very strongly with symptoms in men awaiting their first coronary artery bypass graft. Sleep disturbance (waking fatigued, poor quality sleep, long sleep latency) was found to contribute significantly to exertional, emotional, and post-prandial angina, whereas denial of helplessness and general life dissatisfaction correlated highly with rest and nocturnal angina. ${ }^{8}$

Of the patients in this study, $43 \%$ continued to have the same or worse anginal pain after the second operation, and the survey of published results suggests that this is not an uncommon problem. We would therefore direct the authors' attention to the role of dynamic factors in these patients and the suggestion that the best correlates are biobehavioural. We have long advocated attention to sleep (with sedation) and arousal (by counselling) in patients with angina ${ }^{9}$ as well as avoidance of hyperventilation, which may be the trigger to vasospasm. $^{10}$

Leisa J Freeman,

P G F Nixon,

Cardiac Department,

Charing Cross Hospital (Fulham),

London W6 8RF.

\section{References}

1 Zingone B, Salvi A, Branchini B. Perioperative ischaemia after vein graft surgery. Br Heart $\mathcal{F} 1983$; 49: 280-3.

2 Sowton E. The treatment of angina pectoris Practitioner 1979; 223: 471-6.

3 Clark DA, Quint RA, Mitchell RL, Angell WW. Coronary artery spasm, medical management, surgical denervation, and autotransplantation. $\mathcal{F}$ Thorac Cardiovasc Surg 1977; 73: 332-9.

4 Maseri A, Chiercha S, Davies GJ, Fox KM. Variable susceptibility to dynamic coronary obstruction: an elusive link between coronary atherosclerosis and angina pectoris. $A m \mathcal{F}$ Cardiol 1983; 52: 46a-51a.

5 Petch MC. The progression of coronary artery disease. Br Med F 1981; 283: 1073-4.

6 Kornfeld DS, Heller SS, Frank KA, Wilson SN, Malm JR. Psychological and behavioural responses after coronary artery bypass surgery. Circulation 1982; 66: (suppl III): 24-8.

7 Cooper T, Detre T, Weiss S, et al. Coronary prone behaviour and coronary disease: a critical review Circulation 1981; 63: 1199-215.

8 Jenkins CD, Stanton BA, Klein MD, Savageau JA, Harken DE. Correlates of angina pectoris among men awaiting coronary bypass surgery. Psychosom Med 1983; 45: 141-53.

9 Nixon PGF. Stress and the cardiovascular system. Practitioner 1982; 226: 1589-98.

10 Freeman LJ, Nixon PGF. Chest pain and the hyperventilation syndrome-some aetiological considerations. Postgrad Med F. (In press). 
This letter was shown to Dr Pidgeon, who replies as follows:

Sir,

In our series perioperative myocardial infarction occurred during the first operation in seven patients receiving three vein grafts, four receiving two grafts, and in only one who received a single graft. At reoperation seven of the eight infarcts occurred in patients with three vessel disease. In the Coronary Artery Surgery Study report the incidence of perioperative infarction increased with the number of grafts placed from $2 \cdot 1 \%$ for single grafts to $6.3 \%$ for triple grafts. ${ }^{1}$ Zingone et al report only one case of perioperative infarction in the territory subtended by a normal vessel and cited evidence of a further 11 cases. $^{2}$ We suspect, therefore, that this is not a frequent problem.

With regard to Drs Freeman and Nixon's second comment, all our patients suffered angina provoked by exertion or stress. This would suggest that the fixed obstructive lesions documented at coronary angiography, and confirmed at surgery, were likely to be responsible for their symptoms. In addition, some patients also reported angina at rest, whose genesis may be mediated by the same mechanism. ${ }^{3}$ Moreover, we assessed the severity of symptoms over a prolonged period, usually at least several months, thus circumventing the problem of day to day variability in symptoms. As we stated, symptoms are by definition subjective, although exercise testing is recognised to provoke evidence of ischaemia more readily in the presence of severe disease, both in the native $e^{4}$ and postoperative $e^{5}$ coronary circulation. For this reason we used exercise testing in many patients to aid selection for further investigation. We described the causes of postoperative angina as putative, based on an analysis of the angiograms, from which we determined the feasibility of surgery. The reason for reoperation, however, was to attempt to alleviate severe symptoms.

We noted a high incidence of conventional risk factors in our patients proceeding to reoperation, as do other authors. ${ }^{6}$ Anxiety may provoke angina, and the mechanism for this may be mediated by an increased myocardial oxygen demand. ${ }^{7}$ Although this aspect of the problem may be susceptible to modification of behaviour, our patients were so grossly restricted in terms of physical activity, despite medication, that we considered that coming to terms with their disability offered an inadequate solution. For patients whose disease was deemed inoperable there was no alternative.
We do not deny the role of dynamic and behavioural factors in the genesis of angina, but we question how far they are relevant in this group of patients with significant multivessel fixed obstructive lesions who have symptoms often despite vasodilator treatment. Our experience is that the relief of obstruction by further bypass grafts can produce symptomatic benefit in the majority.

\section{J W Pidgeon, Broadgreen Hospital, Liverpool L14 3LB.}

\section{References}

1 Chaitman BR, Alderman EL. Sheffield T, et al. Use of survival analysis to determine the clinical significance of new $Q$ waves after coronary bypass surgery. Circulation 1983; 67: 302-9.

2 Zingone NB, Salvi A, Branchini B. Perioperative coronary artery spasm leading to myocardial ischaemia after vein graft surgery. $\mathrm{Br}$ Heart $\mathcal{f} 1983 ; 49: 280-3$.

3 Quyyumi AA, Wright C, Mockus L, Fox KM. Effect of partial agonist activity in B blockers in severe angina pectoris: a double blind comparison of pindolol and atenolol. $\mathrm{Br}$ Med F 1984; 289: 951-3.

4 Bartel AG, Behar VS, Peter RH, Orgain ES, Kong Y. Graded exercise stress tests in angiographically documented coronary artery disease. Circulation 1974; 49: 348-56.

5 Gohlke H, Gohlke-Bärwolf C, Samek L, Stürzenofecker P, Schmuziger M, Roskamm H. Serial exercise testing up to six years after coronary bypass surgery: behaviour of exercise parameters in groups with different degrees of revascularisation determined by post-operative angiography. $\mathrm{Am} \mathcal{F} \mathrm{Cardiol} 1983 ; 51$ : 1301-6.

6 Barboriak JJ, Barboriak DP, Anderson AJ, Rimm AA, Tristani FE, Flemma FJ. Risk factors in patients undergoing a second aorta-coronary bypass procedure. $\mathcal{F}$ Thorac Cardiovasc Surg 1978; 76: 111-4.

7 Specchia G, de Servi S, Falcone C, et al. Mental arithmetic stress testing in patients with coronary artery disease. Am Heart $\mathcal{F}$ 1984; 108: 56-63. 